\begin{tabular}{|c|c|c|c|}
\hline$D E$ & \multirow{3}{*}{$\begin{array}{l}\text { DE GRUYTER } \\
\text { OPEN }\end{array}$} & $\begin{array}{l}\text { HUNGARIAN JOURNAL OF } \\
\text { INDUSTRY AND CHEMISTRY }\end{array}$ & \multirow[t]{3}{*}{ 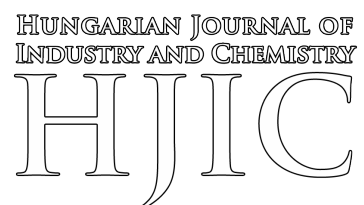 } \\
\hline & & Vol. 44(2) pp. 129-133 (2016) & \\
\hline & & $\begin{array}{l}\text { hjic.mk.uni-pannon.hu } \\
\text { DOI: } 10.1515 / \text { hjic-2016-0016 }\end{array}$ & \\
\hline
\end{tabular}

\title{
METAL-CHLORIDE-ACTIVATED EMPTY FRUIT-BUNCH CARBONS FOR RHODAMINE B REMOVAL
}

\author{
Muhammad AbBas Ahmad ZaINI ${ }^{1,2 *}$ AND Mohd ShafIQ Mohd SHAID ${ }^{1}$ \\ ${ }^{1}$ Faculty of Chemical \& Energy Engineering, Universiti Teknologi Malaysia, Johor Bahru, Johor, \\ 81310, MALAYSIA \\ ${ }^{2}$ Centre of Lipids Engineering \& Applied Research, Ibnu Sina Institute for Scientific \& Industrial \\ Research, Universiti Teknologi Malaysia, Johor Bahru, Johor, 81310, MALAYSIA
}

\begin{abstract}
This study aimed to investigate the adsorptive ability of activated carbons derived from empty boil palm fruitbunch carbons through metal-chloride activation. The derived activated carbons were characterized in terms of yield, $\mathrm{pH}$, surface functional groups, and specific surface area. Rhodamine B dye was used as a pollutant probe to evaluate the performance of activated carbons. Results show that empty, $\mathrm{ZnCl}_{2}$-activated fruit-bunch carbon exhibits a higher surface area of $866 \mathrm{~m}^{2} \mathrm{~g}^{-1}$ and a Rhodamine $B$ removal yield of $105 \mathrm{mg} \mathrm{g}^{-1}$. Activation at the same temperature of $600{ }^{\circ} \mathrm{C}$ using the recovered $\mathrm{FeCl}_{2}$ yields an activated carbon with nearly twice the surface area compared to the fresh one. A direct correlation was obtained between the roles of the specific surface area and removal of Rhodamine B. Empty fruit-bunch carbon is a promising adsorbent precursor for colour removal from water.
\end{abstract}

Keywords: activated carbon, chemical activation, empty fruit-bunch, metal-chloride, Rhodamine B

\section{Introduction}

Malaysia and Indonesia are the leading producers worldwide of palm oil. Due to the growth in palm oil production and despite the high economic returns, this industry also generates a huge amount of was that has negative implications on the environment. As one of the largest oil palm producers in the world, Malaysia generates abundant empty fruit-bunch (EFB) residues amounting to 12.4 million tonnes annually [1].

At present, only a small quantity of EFB is used as fuel for boilers in the oil palm mills while the remaining large quantity is left to decay in fields or disposed of in landfills. Due to the limited area of landfill sites and other associated environmental implications, the quest for the effective utilization of EFB has become a subject of significant interest. Because EFB is rich in carbon and lignin, it has a great potential to be converted into adsorbent or activated carbon for a variety of purification and environmental purposes [2].

Nasir et alia [3] reported the selectivity of methylene blue removal over copper(II) ions by empty fruit-bunch. Yet, the uptake capacity was too small (32.3 mg methylene blue per $\mathrm{g}$ of EFB) to warrant large-scale adsorption operation. In a recent related work, Wirasnita et alia [4] reported the preparation of $\mathrm{ZnCl}_{2}$-activated empty fruit-bunch carbon with a specific surface area of $86.6 \mathrm{~m}^{2} \mathrm{~g}^{-1}$. However, the

*Correspondence: abbas@cheme.utm.my surface area obtained is somewhat small to be regarded as that of activated carbon [5]. There are also reports on the use of $\mathrm{CO}_{2}$ and steam to physically activate the $\mathrm{EFB}$ into activated carbons. However, the surface area is often not controllable and the yield is very low because of high activation temperatures ( 800 to $\left.900{ }^{\circ} \mathrm{C}\right)[6,7]$.

Our present work aimed to evaluate the adsorptive characteristics of metal-chloride-activated empty fruitbunch carbons. Zinc(II) chloride and iron(II) chloride were used for the chemical activation of EFB. Attempts were also made to recover the activator for the second activation. Rhodamine B was used as a model pollutant to establish the adsorption data. The activated carbons were characterized and the adsorptive results compared and discussed.

\section{Experimental}

Oil palm empty fruit-bunch (EFB) was obtained from Sungei Kahang palm oil factory in Johore State, Malaysia. The material was oven-dried at $110^{\circ} \mathrm{C}$ overnight to remove moisture. All chemicals used in the preparation of activated carbons and adsorption were of analytical reagent grade.

\subsection{Preparation of Activated Carbon}

Empty fruit-bunch was loosened and separately modified with zinc chloride and iron(II) chloride in the mass ratio (activator : EFB) of 3:2. Firstly, the activator was dissolved in water, sufficient for the EFB to be immersed. Next, the EFB-activator mixtures were 
stirred at $90{ }^{\circ} \mathrm{C}$ for 40 minutes. After that, the sample was placed in the oven overnight at $110{ }^{\circ} \mathrm{C}$ for impregnation. The impregnated sample was put in a crucible wrapped in aluminium foil, and heated in a furnace for $1.5 \mathrm{~h}$ at $300{ }^{\circ} \mathrm{C}$ and $550{ }^{\circ} \mathrm{C}$ for zinc chloride activation and iron(II) chloride activation, respectively. The selected activation temperatures are half of the boiling points of the activators. The resultant activated carbon was washed with distilled water, and the washed water was used for the second activation using the same impregnation ratio of $3: 2$ at $550{ }^{\circ} \mathrm{C}$ for both activators. Activated carbons were designated as $\mathrm{Z} 1$ and $\mathrm{F} 1$ for activation using fresh zinc(II) chloride and iron(II) chloride, respectively, and Z2 and F2 when using recovered activators, respectively.

\subsection{Characterization of Activated Carbon}

The yield of activated carbon was calculated from the mass of the resultant product over that of the dried EFB used. The adsorbent $\mathrm{pH}$ was determined by soaking $1 \mathrm{~g}$ of adsorbent in $100 \mathrm{~cm}^{3}$ of distilled water. The $\mathrm{pH}$ was measured using a pH meter (HI 8424, Hanna Instruments). The specific surface area of activated carbon was measured using a surface area analyser (Pulse ChemiSorb 2705, Micromeritics) at the temperature of liquid $\mathrm{N}_{2}, 77 \mathrm{~K}$. Fourier transform infrared spectroscopy (FTIR) (IR Tracer-100, Shimadzu) was used to obtain the peaks of functional groups at specific wave numbers ranging from 400 to $4000 \mathrm{~cm}^{-1}$.

\subsection{Adsorption of Rhodamine B}

Rhodamine B of commercial purity was utilized without further purification. $500 \mathrm{mg}$ of Rhodamine B powder was weighed using an analytical balance and then dissolved in $1 \mathrm{dm}^{3}$ of distilled water in a volumetric flask to make up a stock solution. The dilution of stock solution was needed for preparing the working concentrations for adsorption.

Adsorption was performed according to the bottlepoint technique. Briefly, about $0.5 \mathrm{~g}$ of activated carbon was added to $50 \mathrm{~cm}^{3}$ of Rhodamine $\mathrm{B}$ solution at varying concentrations. The mixture was allowed to equilibrate on an orbital shaker at $120 \mathrm{rpm}$ and room temperature for $72 \mathrm{~h}$. The residual concentration was measured using a spectrophotometer (Halo VIS-10, Dynamica Scientific Ltd.) at a wavelength of $555 \mathrm{~nm}$ (absorption unit $=0.014 \times$ concentration, $\mathrm{R}^{2}=0.99$ ). The adsorption capacity $\left(\mathrm{mg} \mathrm{g}^{-1}\right)$ was calculated by a simple material balance (Eq.(1)), and the adsorption data were analysed by general isotherm models, namely Langmuir (Eq.(2)) and Freundlich (Eq.(3)). The respective constants were solved by non-linear regression using Solver as implemented in MS Excel for the smallest sum-of-squared error (SSE) and optimum coefficient of determination $\left(R^{2}\right)$.

$$
q_{\mathrm{e}}=\frac{\left(C_{0}-C_{\mathrm{e}}\right)}{m} V
$$

Table 1. Properties of activated carbons.

\begin{tabular}{llcccc}
\hline activator & \multicolumn{1}{c}{ type } & $\begin{array}{c}\text { temp. } \\
\left({ }^{\circ} \mathrm{C}\right)\end{array}$ & $\begin{array}{c}\text { yield } \\
(\%)\end{array}$ & $\mathrm{pH}$ & $\begin{array}{c}\text { surface area } \\
\left(\mathrm{m}^{2} \mathrm{~g}^{-1}\right)\end{array}$ \\
\hline \multirow{2}{*}{$\mathrm{ZnCl}_{2}$} & Fresh (Z1) & 300 & 44.0 & 3.8 & 2.64 \\
& Recovered (Z2) & 550 & 41.2 & 4.9 & 866 \\
$\mathrm{FeCl}_{2}$ & Fresh (F1) & 550 & 46.8 & 4.6 & 98.4 \\
& Recovered (F2) & 550 & 37.9 & 5.3 & 226 \\
\hline
\end{tabular}

$$
\begin{aligned}
& q_{\mathrm{e}}=\frac{Q b C_{\mathrm{e}}}{1+b C_{\mathrm{e}}} \\
& q_{\mathrm{e}}=K_{\mathrm{F}} C_{\mathrm{e}}^{\frac{1}{\mathrm{n}}}
\end{aligned}
$$

where, $q_{\mathrm{e}}\left(\mathrm{mg} \mathrm{g}^{-1}\right)$ is the adsorption capacity of Rhodamine $\mathrm{B}, C_{o}$ and $C_{e}\left(\mathrm{mg} \mathrm{dm}^{-3}\right)$ are the initial and equilibrium concentrations, respectively, $m(\mathrm{~g})$ is the mass of activated carbon, and $V\left(\mathrm{dm}^{3}\right)$ is the volume of Rhodamine B solution. Constant $Q\left(\mathrm{mg} \mathrm{g}^{-1}\right)$ is the maximum monolayer capacity, $b\left(\mathrm{dm}^{3} \mathrm{~g}^{-1}\right)$ is the adsorption intensity, and $K_{\mathrm{F}}\left(\left(\mathrm{mg} \mathrm{g}^{-1}\right)\left(\mathrm{dm}^{3} \mathrm{mg}^{-1}\right)^{1 / \mathrm{n}}\right)$ and $1 / n$ are the Freundlich constants related to the adsorption capacity and intensity, respectively.

\section{Results and Analysis}

\subsection{Characteristics of Activated Carbons}

Chemical activation using freshly prepared metalchlorides was performed at a temperature of about half of the boiling point of each activator. The boiling point of $\mathrm{ZnCl}_{2}$ and $\mathrm{FeCl}_{2}$ are 723 and $1023{ }^{\circ} \mathrm{C}$, respectively. This is to allow a sufficient amount of activator to be recovered upon activation as it is commonly understood that chemical activators, e.g. $\mathrm{ZnCl}_{2}, \mathrm{KOH}$, etc., are prone to intercalate with the matrix material and/or lost when the activation is done close to the boiling point of the activators. In addition, it enables one to evaluate the effectiveness of activated carbon preparation at the selected temperatures. Table 1 displays the yield, $\mathrm{pH}$, and specific surface area of metal-chloride-activated empty fruit-bunch carbons.

In general, the yield of activated carbons ranges between 38 and $47 \%$. This indicates the underlying role of metal-chlorides as dehydrating agents to enhance the burning off the carbonaceous material. This is also true for $\mathrm{ZnCl}_{2}$ activation at a temperature of $300{ }^{\circ} \mathrm{C}$. In addition, it signifies that a significant portion of metalchlorides could be recovered for the subsequent activation. The $\mathrm{pH}$ values of activated carbons are in the range of 3.8 to 5.3 . The activated carbons are slightly acidic because both metal-chloride activators are Lewis acids. The $\mathrm{pH}$ values were found to increase when the recovered activators were used in the activation. This could be attributed to the decreased amount of metalchlorides that probably could not be fully recovered after the first activation.

From Table 1, the developed surface area of $\mathrm{Z1}$ upon activation is undeniably small, even smaller than for raw EFB $\left(28.4 \mathrm{~m}^{2} \mathrm{~g}^{-1}\right)$ [3]. This could be due to the 


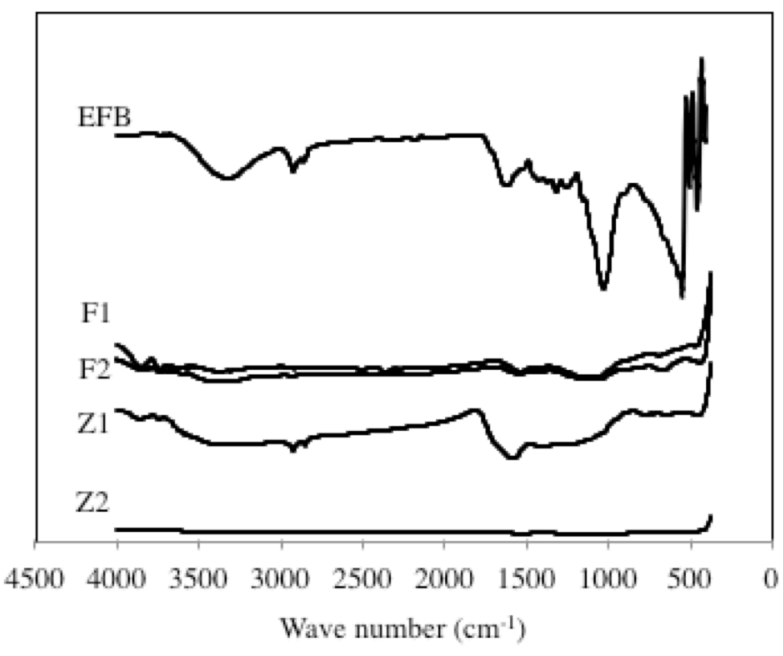

Figure 1. FTIR spectra of EFB and activated carbons.

blockade of existing pore channels because of the intercalation of zinc cations within the material matrix. Intercalation of a chemical activator normally creates new pathways for the porous structure when adequate heat is supplied to the impregnated material. This often results in an increase in pore volume, thus increasing the specific surface area. Yet, the activation temperature for $\mathrm{Z} 1\left(300^{\circ} \mathrm{C}\right)$ may not be sufficient to initiate the job, consequently the activator becomes lodged inside the rudimentary pores even though burning off decreases the activated carbon yield. Therefore, $\mathrm{Z} 1$ could not be regarded as activated carbon because of its inferior development of surface area.

Activation using the recovered activators was performed at $550{ }^{\circ} \mathrm{C}$. There is a tremendous increase in the surface area of $\mathrm{Z} 2$ using the recovered $\mathrm{ZnCl}_{2}$ from Z1. Although the amount of $\mathrm{ZnCl}_{2}$ in the recovered solution is presumably less than for the fresh one (ratio $3: 2$ ), the elevated activation temperature shows a positive effect in increasing the surface area by more than 300 times. This could be related to the fact that more volatiles (nearly $65 \%$ weight loss) are liberated from the empty fruit-bunch at $550^{\circ} \mathrm{C}$ [8]. It is suggested that the liberation of volatiles from the material also contributes to creating the pore pathways. These combined effects bring about the development of activated carbon with a high surface area.

From Table 1, F2 shows a higher surface area than for F1 at the same activation temperature. This could be associated with the optimum impregnation ratio in the preparation of activated carbon. The specific surface area of activated carbon normally increases as the impregnation ratio increases, but decreases when an excessive amount of activator is used. Too much activator may result in the collapse of pore textures, thus decreasing the surface area [9]. In other words, $\mathrm{FeCl}_{2}$ used in the activation of $\mathrm{F} 1$ could have already exceeded the optimum impregnation ratio. However, further experimental works of varying impregnation ratios of $\mathrm{FeCl}_{2}$ are needed to establish the optimum surface area of $\mathrm{FeCl}_{2}$-activated empty fruit-bunch carbons. Nevertheless, F2 demonstrates a 3.8 times
Table 2. Functional groups used in characterizing samples.

\begin{tabular}{llll}
\hline $\begin{array}{l}\text { Wave number } \\
\left(\mathrm{cm}^{-1}\right)\end{array}$ & $\begin{array}{l}\text { Functional } \\
\text { group }\end{array}$ & Type & Sample \\
\hline $3100-3550^{\mathrm{a}}$ & $\mathrm{O}-\mathrm{H}$ & alcohol & EFB, F1, \\
1000 & $\mathrm{C}-\mathrm{O}$ & F2, Z1 \\
2900,2810 & $\mathrm{C}-\mathrm{H}$ & aldehyde & EFB, Z1 \\
1600,1470 & $\mathrm{C}=\mathrm{C}$ & aromatic & EFB, Z1 \\
1600 & $\mathrm{C}=\mathrm{C}$ & alkene & EFB, Z1, \\
3300 & $\mathrm{~N}-\mathrm{H}$ & amine & EFB \\
1300 & $\mathrm{C}-\mathrm{N}$ & & \\
\hline
\end{tabular}

${ }^{a}$ broad feature

lower surface area than $\mathrm{Z} 2$. This shows that $\mathrm{ZnCl}_{2}$ is an effective activator for empty oil palm fruit-bunch-based activated carbon. Fig.1 shows the FTIR spectra of EFB and its derived activated carbons. The designated possible functional groups are summarized in Table 2 .

The spectroscopy technique measures the absorption of various wavelengths of infrared light by materials of interest to identify specific organic functional groups on the surface of activated carbon. From Fig. 1, the EFB displays various peaks that correspond to the presence of functional groups. The broad and strong band at $3300 \mathrm{~cm}^{-1}$ is assigned to the stretching vibration of the $(-\mathrm{OH})$ hydroxyl group. The intensity of the peak decreased by the order of EFB $>$ $\mathrm{Z} 1>\mathrm{F} 1 \approx \mathrm{F} 2>\mathrm{Z} 2$. The peak completely disappeared in $\mathrm{Z} 2$ probably due to the stronger dehydrating effect of $\mathrm{ZnCl}_{2}$ compared to $\mathrm{FeCl}_{2}$ in activating the EFB at 550 ${ }^{\circ} \mathrm{C}$. It also signifies that the activation of $\mathrm{Z} 1$ remains incomplete because most of the attributes of EFB spectra remained unchanged. As the EFB is converted into activated carbon, the complicated peaks become simplified indicating the liberation of functional groups in the activated carbons. The absorption peaks at 2930 $2850 \mathrm{~cm}^{-1}$ are attributed to the $(\mathrm{C}-\mathrm{H})$ stretching vibration of the $\left(-\mathrm{CH}_{3}\right)$ group. The peaks between 1400 and $1000 \mathrm{~cm}^{-1}$ are ascribed to $(\mathrm{C}-\mathrm{O})$ stretching or $(\mathrm{Si}-$ $\mathrm{O})$ of silica containing minerals (ash). The peak at 1026 $\mathrm{cm}^{-1}$ in $\mathrm{Z1}$ is assigned to the out of plane $(\mathrm{C}-\mathrm{H})$ bending.

\subsection{Adsorption of Rhodamine $B$}

Water polluted with dyes especially from the textile industries has become a subject of great concern because of the disruption to biodiversity and food chains [10]. Basic or cationic dyes are very bright dyes that are water-soluble. In this work, Rhodamine $\mathrm{B}$ $\left(\mathrm{C}_{28} \mathrm{H}_{31} \mathrm{C}_{1} \mathrm{~N}_{2} \mathrm{O}_{3}\right.$, $\mathrm{mw}=479 \mathrm{~g} \mathrm{~mol}^{-1}$, solubility in water $=$ $15 \mathrm{~g} \mathrm{dm}^{3}$ ) was chosen as the model dye to evaluate the performance of empty fruit-bunch-based activated carbons. The $\mathrm{pH}$ of the Rhodamine B solution was not adjusted, and the values were measured as $5.1 \pm 0.2$ for all concentrations. At equilibrium, the $\mathrm{pH}$ values slightly changed as they are measured to be $5.3 \pm 0.1$. Fig.2 illustrates the molecular structure of Rhodamine B. 
<smiles>CCN(CC)c1ccc2c(-c3ccccc3C(=O)O)c3ccc(=[N+](CC)CC)cc-3oc2c1</smiles>

Figure 2. Chemical structure of cationic Rhodamine B dye.

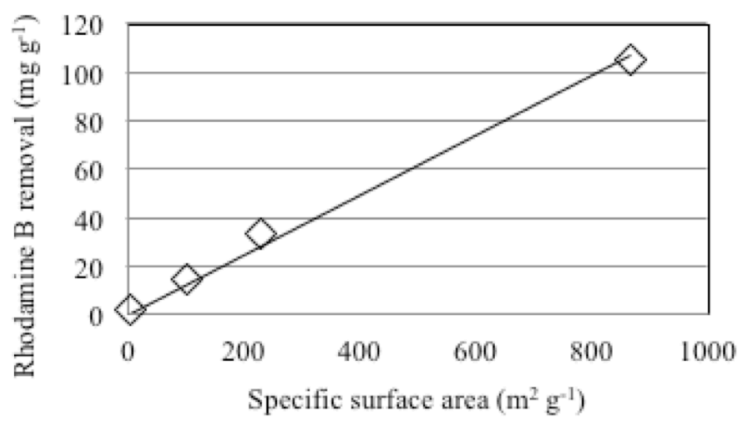

Figure 4. Correlation between Rhodamine B removal and specific surface area.

Table 3. Parameters of isotherm models.

\begin{tabular}{crrrr}
\hline & \multicolumn{1}{c}{$\mathrm{Z} 1$} & \multicolumn{1}{c}{$\mathrm{Z} 2$} & \multicolumn{1}{c}{$\mathrm{F} 1$} & \multicolumn{1}{c}{$\mathrm{F} 2$} \\
\hline$Q_{\text {exp }}\left(\mathrm{mg} \mathrm{g}^{-1}\right)$ & 2.33 & 105 & 14.8 & 33.4 \\
Langmuir model & & & & \\
$Q\left(\mathrm{mg} \mathrm{g}^{-1}\right)$ & 2.85 & 97.9 & 18.5 & 42.2 \\
$b\left(\mathrm{dm}^{3} \mathrm{~g}^{-1}\right)$ & 0.166 & 2.92 & 0.248 & 0.187 \\
$R^{2}$ & 0.907 & 0.434 & 0.857 & 0.967 \\
$S S E$ & 0.233 & 403 & 23.7 & 26.3 \\
Freundlich model & & & & \\
$\mathrm{K}_{\mathrm{F}}\left(\mathrm{mg} \mathrm{g}^{-1}\right)\left(\mathrm{L} \mathrm{mg}^{-1}\right)^{1 / \mathrm{n}}$ & 0.560 & 72.5 & 4.73 & 8.86 \\
$\mathrm{n}$ & 2.10 & 13.4 & 2.61 & 2.33 \\
$R^{2}$ & 0.882 & 0.707 & 0.718 & 0.869 \\
$S S E$ & 0.435 & 209 & 44.7 & 94.3 \\
\hline
\end{tabular}

Fig.3 shows the removal of Rhodamine B by EFBderived materials. From Fig.3, the removal of Rhodamine $\mathrm{B}$ was found to increase with concentration by the order of $\mathrm{Z} 2>\mathrm{F} 2>\mathrm{F} 1>\mathrm{Z} 1$. Activated carbon $\mathrm{Z} 2$ demonstrates the highest Rhodamine $B$ removal of $105 \mathrm{mg} \mathrm{g}^{-1}$. This trend is in agreement with the increase in specific surface area of adsorbents. In general, the concentration of dye in the solution provides a driving force for adsorption if the adsorbent or activated carbon possesses abundant active sites. In this case, the active sites are directly associated with the surface area. Fig.4 displays the correlation between the removal of Rhodamine $\mathrm{B}$ and the surface area.

A linear relationship for Rhodamine $B$ removal $\left(\mathrm{mg} \mathrm{g}^{-1}\right)=0.124 \times$ specific surface area $\left(\mathrm{m}^{2} \mathrm{~g}^{-1}\right), R^{2}=$ 0.993 was obtained. A bigger surface area normally provides better interaction probabilities for the Rhodamine B molecules to lodge onto the pore channels. In addition, it is presumed that all types of pore play a dominating role in the adsorption especially mesopores [5,11].
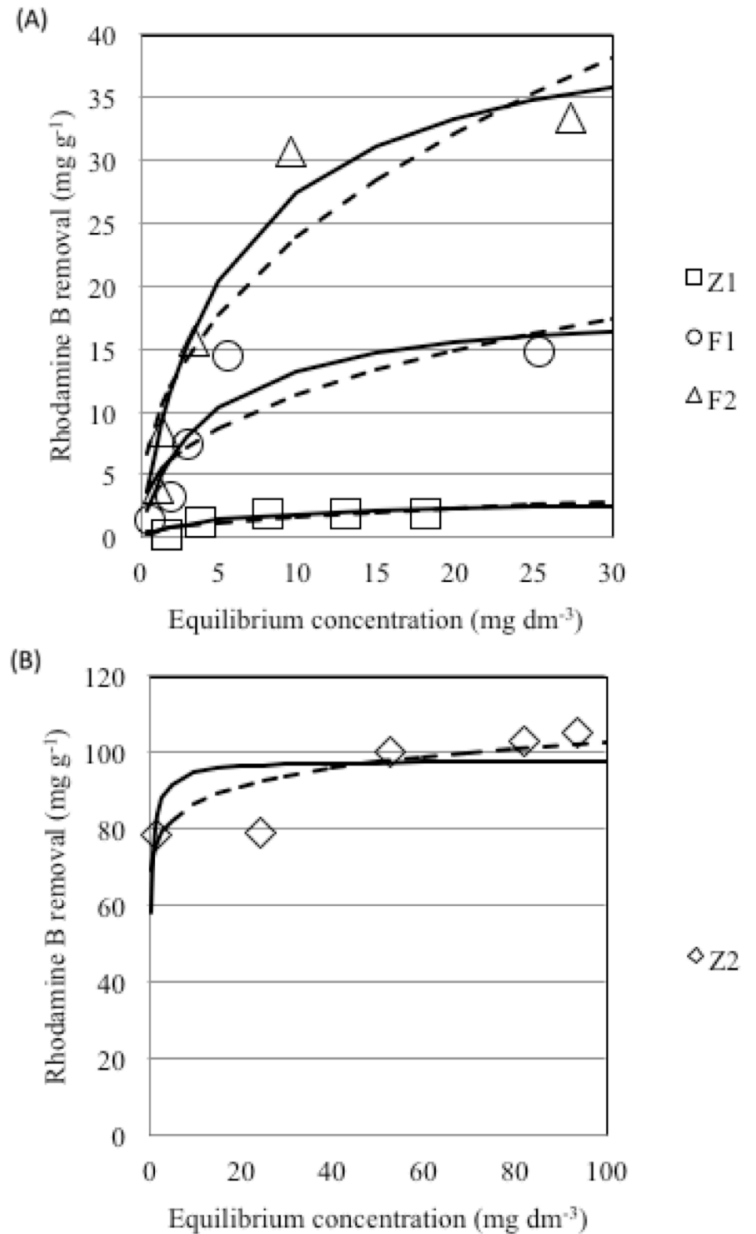

Figure 3. Removal of Rhodamine B by (A) Z1, F1 and F2, and (B) Z2. Lines were predicted by the Langmuir (solid) and Freundlich (dashed) models.

The adsorption data were analysed using the Langmuir and Freundlich models, and the constants are tabulated in Table 3. The adsorption data reasonably fitted to both adsorption models with $R^{2}$ ranging between 0.71 and 0.97 , except for $\mathrm{Z} 2$ according to the Langmuir model. The values of Langmuir model capacity $(Q)$ are in close proximity to the experimental data $\left(Q_{\text {exp }}\right)$. In addition, Z2 shows a higher adsorption affinity $(b)$ for Rhodamine B when compared with the other counterparts. This signifies a higher removal efficiency ( $99 \%)$ at concentrations below $80 \mathrm{mg} \mathrm{dm}^{-3}$. Similar explanations apply for the Freundlich model. The deviation of the lines of the model from the experimental data is shown in Fig.3, which indicates that the removal of Rhodamine $\mathrm{B}$ by EFB-based materials is neither a strict monolayer adsorption nor heterogeneous coverage, but could be a blend of the two - monolayer adsorption onto a heterogeneous surface [11].

In a related work, Santhi et alia [12] reported a removal capacity of $22.3 \mathrm{mg} \mathrm{g}^{-1}$ of Rhodamine B using $\mathrm{H}_{2} \mathrm{SO}_{4}$-treated A. nilotica leaves. Generally, $\mathrm{Z} 2$ shows a higher dye removal capacity compared to this chemically treated natural adsorbent. This is likely due to the well-developed graphitic structure and surface area of $\mathrm{Z} 2$ for the effective removal of Rhodamine B. 


\section{Conclusion}

Oil palm empty fruit-bunch was used in the preparation of activated carbons via metal-chloride activation. Zinc chloride is a more effective activating agent for activated carbon than iron(II) chloride. Activation at $500{ }^{\circ} \mathrm{C}$ yields empty fruit-bunch-based activated carbon with a surface area of $866 \mathrm{~m}^{2} \mathrm{~g}^{-1}$. A bigger surface area offers greater removal of Rhodamine B dye and a higher adsorption affinity at lower dye concentrations. The maximum removal efficiency was recorded as $105 \mathrm{mg}$ $\mathrm{g}^{-1}$. The mechanism could be described as monolayer Rhodamine B adsorption onto heterogeneous activated carbon. Empty fruit-bunch is a promising alternative to activated carbon precursors for wastewater treatment.

\section{Acknowledgement}

The research was supported by Universiti Teknologi Malaysia through Tier One Research Grant \#10H42.

\section{REFERENCES}

[1] Tanaka, R.; Rosli, W.; Magara, K.; Ikeda, T.; Hosoya, S.: Chlorine-free bleaching of Kraft pulp from oil palm empty fruit-bunches, Jpn. Agric. Res. 2004 38(4), 275-279 DOI: 10.6090/jarq.38.275

[2] Duan, X.; Peng, J.; Srinivasakannan, C.; Zhang, L.; Xia, H.; Yang, K.; Zhang, Z.: Process optimization for the preparation of activated carbon from Jatropha hull using response surface methodology, Energy Sources, Part A: Recovery Util. Environ. Effect, 2011 33(21), 2005-2017 DOI: 10.1080/ 15567030903515047

[3] Nasir, N.H.M.; Zaini, M.A.A.; Setapar, S.H.M.; Hassan, H.: Removal of methylene blue and copper(II) by oil palm empty fruit-bunch sorbents, J. Teknologi 2015 74(7), 107-110 DOI: 10.11113/ jt.v74.4707

[4] Wirasnita, R.; Hadibarata, T.; Yusoff, A.R.M.; Lazim, Z.M.: Preparation and characterization of activated carbon from oil palm empty fruit-bunch wastes using zinc chloride, J. Teknologi 2015 74(11), 77-81 DOI: 10.11113/jt.v74.4876
[5] Ming-Twang, S.; Lin-Zhi, L.; Zaini, M.A.A.; ZhiYong, Q.; Pei-Yee, A.Y.: Activated carbon for dyes adsorption in aqueous solution, In: Advances in Environmental Research, Ed.: Daniels. J.A. (Nova Science Publishers, Inc., New York, USA) pp. 217-234, 2015

[6] Hidayu, A.R.; Mohamad, N.F.; Matali, S.; Sharifah, A.S.A.K.: Characterization of activated carbon prepared from oil palm empty fruit-bunch using BET and FT-IR techniques, Proc. Engng. 2013 68, 379-384 DOI: 10.1016/j.proeng.2013.12.195

[7] Alam, M.Z.; Ameem, E.S.; Muyibi, S.A.; Kabbashi, N.A.: The factors affecting the performance of activated carbon prepared from oil palm empty fruit-bunches for adsorption of phenol, Chem. Engng. J. 2009 155(1-2), 191-198 DOI: 10.1016/j.cej.2009.07.033

[8] Nyakuma, B.B.; Johari, A.; Ahmad, A.; Abdullah, T.A.T.: Thermogravimetric analysis of the fuel properties of empty fruit-bunch briquettes, $J$. Teknologi 2014 67(3), 79-82 DOI: 10.11113/jt.v67.2768

[9] Zaini, M.A.A.; Okayama, R.; Machida, M.: Adsorption of aqueous metal ions on cattlemanure-compost based activated carbons, $J$. Hazard Mater. 2009 170(2-3), 1119-1124 DOI: 10.1016/j.jhazmat.2009.05.090

[10] Ming-Twang, S.; Zhi-Yong, Q.; Lin-Zhi, L.; PeiYee, A.Y.; Zaini, M.A.A.: Dyes in water: Characteristics, impacts to the environment and human health, and the removal strategies. In: Advances in Chemistry Research, Ed.: Taylor, J.C. (Nova Science Publishers, Inc., New York, USA) Vol. 23, pp. 143-156, 2015

[11]Zaini, M.A.A.; Zakaria, M.; Setapar, S.H.M.; Yunus, M.A.C.: Sludge-adsorbents from palm oil mill effluent for methylene blue removal, $J$. Environ. Chem. Engng. 2013 1(4), 1091-1098 DOI: 10.1016/j.jece.2013.08.026

[12] Santhi, T.; Prasad, A.L.; Manonmani, S.: A Comparative study of microwave and chemically treated acacia Nilotica leaf as an eco-friendly adsorbent for the removal of Rhodamine B dye from aqueous solution, Arabian J. Chem. 2014 7(4), 494-503 DOI: 10.1016/j.arabjc.2010.11.008 